\title{
Forecasting Parameter Estimates: A Modeling Approach Using Exponential and Linear Regression
}

\author{
W. M. A. W. Ahmad \\ School of Dental Sciences \\ Universiti Sains Malaysia, Malaysia \\ wmamir@usm.my
}

\author{
R. A. A. Rohim \\ Universiti Sains Malaysia \\ Malaysia \\ adawiyah5350@yahoo.com
}

\author{
N. H. Ismail \\ Universiti Sains Malaysia \\ Malaysia \\ noorhuda@usm.my
}

\begin{abstract}
This paper supplies a calculation method for the parameter estimates of an exponential equation through SAS algorithm. The aim of this paper is to investigate the efficiency of the gained parameter estimates through the forecasting performance. The proposed calculation method can provide a very useful technique to develop an exponential equation with better accuracy performance. This research paper illustrates a sample of the data obtained from the established study, which characterize the proliferative capacity of mesenchymal stem cells. This paper also provides the specific algorithm for the parameter estimates.
\end{abstract}

\section{Keywords-exponential; SAS algorithm; parameter estimates}

\section{INTRODUCTION}

Regression analysis is a statistical methodology that uses the relationship between two or more quantitative variables in a way that one variable can be predicted from the other, or others. This methodology is widely used in business, social, behavioral and biological sciences, including agriculture and fishery research [1]. For example, fish weight at harvest can be predicted by utilizing the relationship between fish weights and other growth affecting factors like water temperature, dissolved oxygen, and free carbon dioxide. There are other situations in a fishery where relationships among variables can be exploited through regression analysis [1]. Regression analysis serves three major purposes: (1) description, (2) control and (3) prediction. We frequently use equations to summarize or describe data. Regression analysis is helpful in developing such equations. For example, we may collect a considerable amount of fish growth data and a data on a number of biotic and abiotic factors and a regression model would probably be a much more convenient and useful summary of those data than a table or a graph. Besides prediction, regression models may be used for control purposes. A cause and effect relationship may not be necessary if the equation is to be used only for prediction [2]. A functional relationship between two variables is expressed by a mathematical formula. If $x$ denotes the independent variable and $\mathrm{y}$ the dependent variables, a functional relationship is of the form $y=f(\mathrm{x})$.

Given a particular value of $x$, the function indicates the corresponding value of $y$. A statistical relation, unlike a function, is not a perfect one. In general, the observations for a statistical relation do not fall directly on the relationship's curve. Depending on the nature of the relationship between $x$ and $y$, regression approach may be classified into two categories, linear regression and nonlinear regression models. The models that are linear in these parameters are known as linear models, whereas in nonlinear models parameters show nonlinearity. Linear models are generally satisfactory approximations for most regression applications. There are occasions, however, when an empirically indicated or a theoretically justified nonlinear model is more appropriate [3].

\section{A. Linear Regression}

Linear regression is used to study the linear relationship between a dependent variable $\mathrm{Y}$ and one or more independent variables $\mathrm{X}$. The dependent variable $\mathrm{Y}$ must be continuous, while the independent variables may be either continuous, binary, or categorical. The initial judgment of a possible relationship between two continuous variables should always be made on the basis of a scatter plot (scatter graph). This type of plot will show whether the relationship is linear or nonlinear. Performing a linear regression makes sense only if the relationship is linear. Other methods must be employed to study nonlinear relationships [4]. A model with more than predictor variables is a straightforward one. The model can be stated as follows:

$$
y_{i}=\beta_{0}+\beta_{1} x_{i}+\varepsilon_{\mathrm{i}}
$$

where $y_{\mathrm{i}}$ is the value of the response variable in the $i^{\text {th }}$ trial, $\beta_{0}$ and $\beta_{1}$ are parameters $x_{i}$ is a known constant, namely the $\mathrm{i}^{\text {th }}$ value of the predictor variable and $\varepsilon_{i}$ is a random error term with mean zero and variance $\sigma^{2}$ and their covariance is zero [5].

\section{B. History of the Exponential Function}

The exponential is one of the most significant and widely occurring functions. In biology, it may depict the growth of bacteria or animal populations, the reduction of the number of bacteria in response to a sterilization process, the development of a tumor or the absorption or elimination of a drug. Exponential growth cannot go on forever because of limitations of nutrients, etc. Knowledge of the exponential function makes it more comfortable to understand birth and death rates, even when they are not perpetual. In physics, the exponential function describes the disintegration of radioactive nuclei, the 
emission of light by atoms, the assimilation of light as it passes through matter, the change of voltage or current in some electrical circuits, the variance of temperature with time as a warm object cools, and the rate of some chemical reactions [1]. Although the exponential distribution provides a simple, elegant and closed form solution to many problems, it does not offer a reasonable parametric fit for some practical applications where the underlying failure rates are nonconstant, presenting monotone shapes. Recently, in the procedure of overcoming such problems, new categories of examples were introduced based on adjustments of the exponential distribution. Authors in [6] offered a generalized exponential distribution, which can hold data with increasing and decreasing failure rate function. Authors in [7] ushered in the exponential geometric distribution with decreasing failure rate, authors in [8] proposed a twoparameter distribution known as exponential-Poisson distribution, which takes in a decreasing failure rate and authors in [3] proposed another modification of the exponential distribution with decreasing failure rate function This model is inferred in a complementary risk scenario [9] where the lifetime associated with particular danger is not evident, rather we observe just the maximum lifetime value among all risks .

\section{Exponential Growth}

Exponential growth is often used to model the growth of organism populations in a resource-rich environment. Here "resource-rich" means that there is abudance of food and other resources necessary for the population to grow. For example, the initial growth of a cell bacteria in a mouth is often modeled as exponential. The justification for this model is that the rate at which a population of organisms grows should be proportional to their number, assuming that the organisms reproduce at a constant rate. For example, if you double the size of a population, then this should precisely double the rate at which the population bears an offspring, and should, therefore, double the rate at which the size of the population increases. What this means is that the population $\mathrm{A}$ of a given organism in a resource-rich environment should satisfy the differential equation

$$
\frac{d A}{d x}=A x,
$$

where $x$ is some constant that depends on the rate of reproduction. Thus the population grows exponentially

$$
A=A_{0} e^{b x}
$$

This model predicts that the population $A$ will grow indefinitely, which cannot be true in any real situation. Eventually, any population will run out of resources such as food or space to grow. However, the exponential model often gives fairly accurate results in cases where the short-term growth of a population is not inhibited by limited resources[10].

\section{Interpreting $R^{2}$}

$R^{2}$ is frequently defined as the proportion of variance of the response that is predictable (or explained) from the regressor variables, that is the variability explained by the model. A low value of $R^{2}$ can suggest that the assumptions of linear regression are not satisfied. Plots and diagnostics will substantiate this suspicion.

\section{MATERIALS AND METHODS}

We used the data which characterize the proliferative capacity of mesenchymal stem cells. The data are composed of two variables which are the days of the culture $(X)$ and population doubling level $(\ln Y)$. First, we bootstrap the data in order to increase the sample size and also to optimize the parameter estimates. Then, we estimate the parameters through the exponential curve fitting and transform the nonlinear model into a linear form. This would bring a linear equation form. From the equation, we estimate the value of the independent variable $(x)$ and fit the data with robust weighted regression by Cauchy, robust Fair weighted regression and robust weighted regression by Huber. Then a covariate-dependent variable is used to examine the differences in performance of the model suitability.

\section{A. The Algorithm of Exponential Calculation}

The algorithm showed below is the way of inserting data in SAS algorithm and the way of calculating the bootstrapping method.

- Data in SAS format. The name of the dataset is given as cell_growth. The data consist of two variables $x$ and $\ln y$

Data cell growth; input x y lny;

cards;

$\begin{array}{lll}0.00 & 38.00 & 3.64\end{array}$

$\begin{array}{lll}5.00 & 39.31 & 3.67\end{array}$

$\begin{array}{lll}8.00 & 39.74 & 3.68\end{array}$

$\begin{array}{lll}10.00 & 40.98 & 3.71\end{array}$

$\begin{array}{lll}13.00 & 43.10 & 3.76\end{array}$

$\begin{array}{lll}17.00 & 45.78 \quad 3.82\end{array}$

$\begin{array}{lll}20.00 & 49.15 & 3.89\end{array}$

$22.00 \quad 49.90 \quad 3.91$

$\begin{array}{lll}24.00 & 53.98 & 3.99\end{array}$

$28.00 \quad 57.46 \quad 4.05$

$31.00 \quad 61.03 \quad 4.11$

$34.00 \quad 63.80 \quad 4.16$

$37.00 \quad 65.52 \quad 4.18$

$\begin{array}{lll}40.00 & 68.54 & 4.23\end{array}$

$\begin{array}{lll}44.00 & 72.62 & 4.29\end{array}$

$\begin{array}{lll}47.00 & 75.42 & 4.32\end{array}$

$\begin{array}{lll}50.00 & 79.38 & 4.37\end{array}$

$\begin{array}{lll}53.00 & 83.31 & 4.42\end{array}$

run;

- Adding bootstrapping algorithm to the methodology building. cell growth data were bootstrapped two times with resampling. The following procedure was given in SAS syntax as follows. The new data which are generated by the SAS procedure will be named as booted. The produce data in the study will be print through the print procedure.

- We also add the syntax of 'ods rtf file='abc.rtf' style=journal' in the SAS language in order to get the output in Microsoft Word format.

$\%$ MACRO bootstrap $($ data $=$ last_, booted $=$ booted, boots $=2$, 
seed $=1234)$;

DATA \&booted;

pickobs $=$ INT $($ RANUNI $(\&$ seed $) * n)+1$;

ET \&data POINT $=$ pickobs $\mathrm{NOBS}=\mathrm{n}$;

REPLICATE $=\operatorname{int}(\mathrm{i} / \mathrm{n})+1$;

$\mathrm{i}+1$;

IF i $>$ n*\&boots THEN STOP;

RUN;

$\%$ MEND bootstrap

ods rtf file='abc.rtf' style=journal;

$\%$ bootstrap $($ data $=$ cell_growth, boots $=2)$;

run;

proc print data $=$ booted;

run;

- PROC SQL is a procedure developed in SQL. We can use this procedure to adjust, retrieve and report data in tables and views. SAS will create the output in the form of tables.

- The syntax below shows the calculation of the corrected sum of squares and the exponential parameter estimates. Through the syntax provided, we are able to measure the fitness of the parameter through the R-Square and AIC value.

Title "CORRECTED SUM OF SQUARES";

proc sql;

select css(y) into :CORRECTED_SUM_OF_SQUARESy from cell growth;

quit;

Title "EXPONENTIAL PARAMETER ESTIMATES";

ods graphics/imagename="ExponentialFit";

proc nlin data $=$ booted plots $=$ fit;

parameters $\mathrm{A}=1 \mathrm{~b}=0$;

model $\mathrm{y}=\mathrm{A} * \exp \left(\mathrm{b}^{*} \mathrm{x}\right)$;

ods output EstSummary=summExp;

run;

proc sql;

select N.nValue1 as n,

SSE.nValue1 as SSE

1 -SSE/\&CORRECTED_SUM_OF_SQUARESy as RSquare,

$\mathrm{n} * \log (\mathrm{SSE} / \mathrm{n})+2 * 2$ as AIC from summExp as SSE,

summExp as $\mathrm{N}$

where N.Label1="Observations Used" and

SSE.Label1="Objective"; quit;

B. The Syntax of Regression Modeling Based on Four Types of Calculation

- Calculation regression based on robust regression. The full syntax is given as follows.

Title "REGRESSION";

/* ROBUST REGRESSION */

procrobustreg method $=\mathrm{mm}$ data $=$ booted;

model lny $=\mathrm{x} /$ diagnostics leverage;

output out=robout $r=$ resid $\mathrm{sr}=$ stdres;

run;

- Calculation regression based on robust (weighted) Huber.

The full syntax is given as follows.

/* ROBUST (WEIGHTED) HUBER */

Title "ROBUST (WEIGHTED) HUBER";

procrobustreg method $=\mathrm{m}(\mathrm{wf}=$ huber $(\mathrm{c}=1.345))$ data=booted; model lny $=\mathrm{x} /$ diagnostics leverage; output out=robout $\mathrm{r}=$ resid $\mathrm{sr}=$ stdres;

run;

- Calculation regression based on robust (weighted) Cauchy.

The full syntax is given as follows.

/* ROBUST (WEIGHTED) CAUCHY */

Title "ROBUST (WEIGHTED) CAUCHY",

procrobustreg method $=\mathrm{m}(\mathrm{wf}=$ cauchy $(\mathrm{c}=2.385))$ data $=$ booted;

model lny $=\mathrm{x} /$ diagnostics leverage;

output out=robout $\mathrm{r}=$ resid $\mathrm{sr}=$ stdres;

run;

- Calculation regression based on robust (weighted) Fair. The full syntax is given as follows.

/* ROBUST (WEIGHTED) FAIR */

Title "ROBUST (WEIGHTED) FAIR";

procrobustreg method $=\mathrm{m}(\mathrm{wf}=$ fair $(\mathrm{c}=1.4))$ data $=$ booted;

model lny $=\mathrm{x} /$ diagnostics leverage;

output out=robout $\mathrm{r}=$ resid $\mathrm{sr}=$ stdres;

run;

ods rtf close;

The syntax of "ods rtf close" gives an order to close the file in Microsoft Word. This means that the output will be generated in the Microsoft Word format.

\section{RESULTS}

The results for the first model without involving weighted procedures is given in Tables I and II. Table I shows that the model predicts the dependent variable well. The p-value is less than 0.05 , and this indicates that, overall, the model statistically significantly predicts the outcome variable and is a good fit for the data. Figure 1, indicates the fit plot for lny.

\section{A. Result for Exponential Fit}

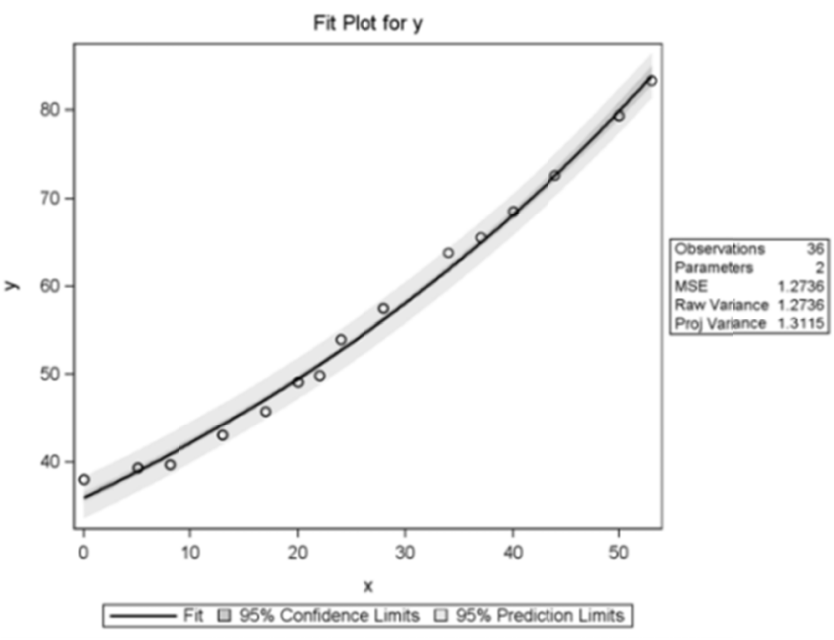

Fig. 1. The fit plot for $\mathrm{y} v \mathrm{vs}$

TABLE I. ANOVA

\begin{tabular}{|c|c|c|c|c|c|}
\hline Source & DF & $\begin{array}{c}\text { Sum of } \\
\text { Squares }\end{array}$ & $\begin{array}{c}\text { Mean } \\
\text { Square }\end{array}$ & F Value & $\begin{array}{c}\text { Approx } \\
\text { Pr }>\text { F }\end{array}$ \\
\hline Model & 2 & 100489 & 50244 & 39450.4 & $<.0001$ \\
\hline Error & 34 & 43.3029 & 1.273 & & \\
\hline Total & 36 & 100533 & & & \\
\hline
\end{tabular}


TABLE II. PARAMETER ESTIMATES

\begin{tabular}{|c|c|c|c|c|}
\hline Parameter & Estimate & $\begin{array}{c}\text { Approx } \\
\text { Std. Error }\end{array}$ & \multicolumn{2}{|c|}{$\begin{array}{c}\text { Approximate 95\% } \\
\text { Confidence Limits }\end{array}$} \\
\hline A & 35.9735 & 0.2564 & 35.4525 & 36.4945 \\
\hline b & 0.0160 & 0.000219 & 0.0155 & 0.0164 \\
\hline
\end{tabular}

From Table II, we can write an exponential model as

$$
y=35.9735 e^{0.0160 x}
$$

Model (2) can be transformed into a linear form by taking, it can be written as follows

$$
\begin{aligned}
& \ln (y)=\ln (35.9735)+0.0160 x \\
& \ln (y)=3.5827+0.0160 x
\end{aligned}
$$

Table III gives the information of exponential fit. From Table III, the R-square value indicates how much of the total variation in the dependent variable or variability of the data is explained by the regression model. In this case, 97.98 can be explained, which is very large. The AIC value is about 10.649, which is the smallest value among all proposed methods. A good model is the one that has minimum AIC value.

TABLE III. EXPONENTIAL FIT

\begin{tabular}{|c|c|c|c|}
\hline $\mathbf{n}$ & SSE & R-Square & AIC \\
\hline 36 & 43.302936 & 0.988339 & 10.64925 \\
\hline
\end{tabular}

\section{B. Result for Robust Regression}

Figure 2 shows the fit plot for lny vs x. Previously we used the original data, while in this section we are using the transformed data. Table IV shows the parameter estimates. We can write an exponential model as:

$$
\ln y=3.5729+0.0162 x
$$

The R-Square value indicates the total variation in the dependent variable. In this case, 78.94 can be explained and the value of AIC is given as 28.24. Detailed information is given in Table V.

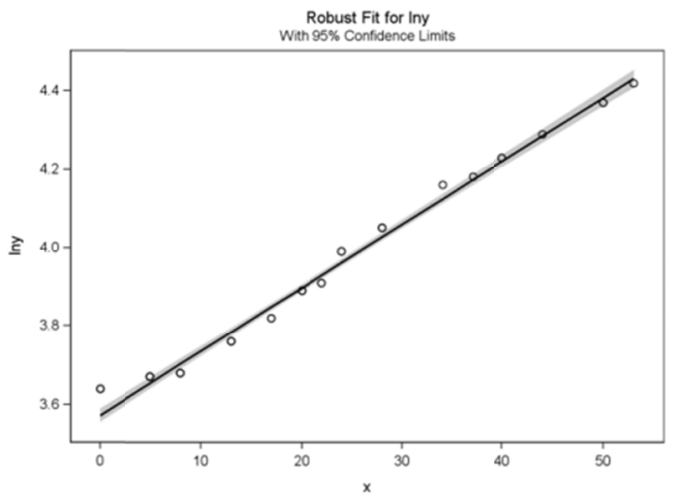

Fig. 2. Fit plot for lny

\section{Result for Robust (Weighted) Huber}

Figure 3 gives the plot for lny vs $\mathrm{x}$ for Huber robust regression. From the Table VI, we can write a robust regression which is weighted by Huber as:

$$
\ln y=3.5799+0.0160 x
$$

From the robust regression which is weighted by Huber, the value of R-Square is 0.9577 and AIC value is given as 24.3544 .

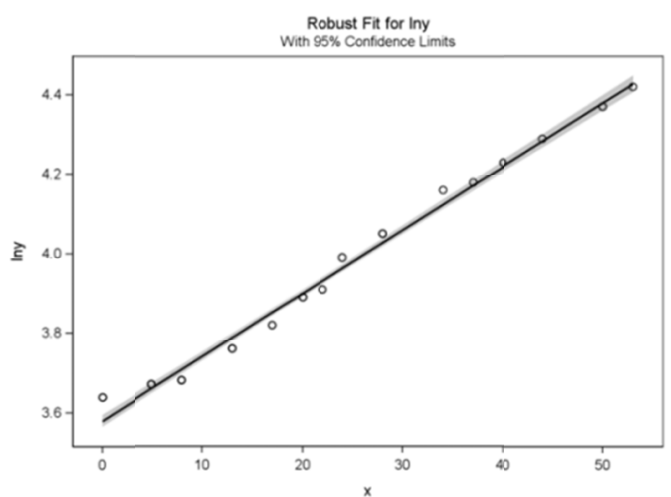

Fig. 3. Fit plot for lny

TABLE IV. PARAMETER ESTIMATES

\begin{tabular}{|c|c|c|c|c|c|c|c|}
\hline \multicolumn{7}{|c|}{ Parameter Estimates } \\
\hline Parameter & DF & Estimate & $\begin{array}{c}\text { Std. } \\
\text { Error }\end{array}$ & $\begin{array}{c}\text { 95\% } \\
\text { Confidence } \\
\text { Limits }\end{array}$ & $\begin{array}{c}\text { Chi- } \\
\text { Square }\end{array}$ & $\begin{array}{c}\text { Pr }> \\
\text { Chi.Sq. }\end{array}$ \\
\hline Intercept & 1 & 3.5729 & 0.0087 & 3.554 & 3.590 & 168673 & $<0001$ \\
\hline $\mathrm{x}$ & 1 & 0.0162 & 0.0003 & 0.016 & 0.017 & 2383.2 & $<0001$ \\
\hline Scale & 0 & 0.0282 & & & & & \\
\hline
\end{tabular}

TABLE V. PARAMETER ESTIMATION

\begin{tabular}{|c|c|}
\hline \multicolumn{2}{|c|}{ Goodness-of-Fit } \\
\hline Statistic & Value \\
\hline R-Square & 0.7894 \\
\hline AICR & 28.2413 \\
\hline BICR & 32.9392 \\
\hline Deviance & 0.0205 \\
\hline
\end{tabular}

\section{Result for Robust (Weighted) Cauchy}

In Figure 4 the result of robust regression which is weighted by Cauchy is plotted. From Table VIII, we can write a robust regression which is weighted by Huber as follows

$\ln y=3.5798+0.0160 x$

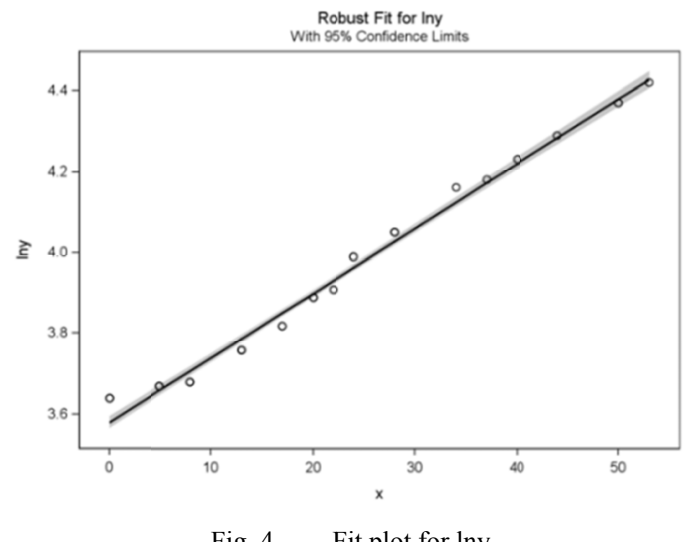

Fig. 4. Fit plot for lny 
The value of R-Square is 0.4797 and AIC value is given as 377.98. A robust regression which is weighted by Cauchy seems not to be a good procedure for the forecasting.

TABLE VI. PARAMETER ESTIMATES FOR HUBER REGRESSION

\begin{tabular}{|c|c|c|c|c|c|c|c|}
\hline \multicolumn{7}{|c|}{ Parameter Estimates } \\
\hline Parameter & DF & Estimate & $\begin{array}{c}\text { Std. } \\
\text { Error }\end{array}$ & $\begin{array}{c}\text { 95\% } \\
\text { Confidence } \\
\text { Limits }\end{array}$ & $\begin{array}{c}\text { Chi- } \\
\text { Square }\end{array}$ & $\begin{array}{c}\text { Pr }> \\
\text { ChiSq. }\end{array}$ \\
\hline Intercept & 1 & 3.5799 & 0.0076 & 3.5651 & 3.594 & 222668 & $<.0001$ \\
\hline $\mathrm{x}$ & 1 & 0.0160 & 0.0003 & 0.0154 & 0.016 & 2807.09 & $<.0001$ \\
\hline Scale & 1 & 0.0335 & & & & & \\
\hline
\end{tabular}

TABLE VII. PARAMETER ESTIMATES FOR HUBER REGRESSION

\begin{tabular}{|c|c|}
\hline \multicolumn{2}{|c|}{ Goodness-of-Fit } \\
\hline Statistic & Value \\
\hline R-Square & 0.9577 \\
\hline AICR & 24.3544 \\
\hline BICR & 29.2774 \\
\hline Deviance & 0.0249 \\
\hline
\end{tabular}

TABLE VIII. PARAMETER ESTIMATES FOR CAUCHY REGRESSION

\begin{tabular}{|c|c|c|c|c|c|c|c|}
\hline \multicolumn{7}{|c|}{ Parameter Estimates } \\
\hline Parameter & DF & Estimate & $\begin{array}{c}\text { Std. } \\
\text { Error }\end{array}$ & $\begin{array}{c}\mathbf{9 5 \%} \\
\text { Confidence } \\
\text { Limits }\end{array}$ & $\begin{array}{c}\text { Chi- } \\
\text { Square }\end{array}$ & $\begin{array}{c}\text { Pr > } \\
\text { ChiSq. }\end{array}$ \\
\hline Intercept & 1 & 3.5798 & $\begin{array}{c}0.008 \\
0\end{array}$ & $\begin{array}{c}3.564 \\
2\end{array}$ & $\begin{array}{c}3.59 \\
5\end{array}$ & 201478 & $<0.0001$ \\
\hline $\mathrm{x}$ & 1 & 0.0160 & $\begin{array}{c}0.000 \\
3\end{array}$ & $\begin{array}{c}0.015 \\
4\end{array}$ & $\begin{array}{c}0.01 \\
6\end{array}$ & 2540.99 & $<0.0001$ \\
\hline Scale & 1 & 0.0336 & & & & & \\
\hline
\end{tabular}

TABLE IX. PARAMETER ESTIMATES FOR CAUCHY REGRESSION

\begin{tabular}{|l|l|}
\hline \multicolumn{2}{|c|}{ Goodness-of-Fit } \\
\hline Statistic & Value \\
\hline R-Square & 0.4797 \\
\hline AICR & 377.9854 \\
\hline BICR & 383.0731 \\
\hline Deviance & 0.4252 \\
\hline
\end{tabular}

\section{E. Result for Robust (Weighted) Fair}

Below is the result of Fair robust regression. From Table X, we can write a fair robust regression is given in (6). The value of R-Square is 0.9616 and AIC value is given 12.309.

$$
\ln y=3.5803+0.0160 x
$$

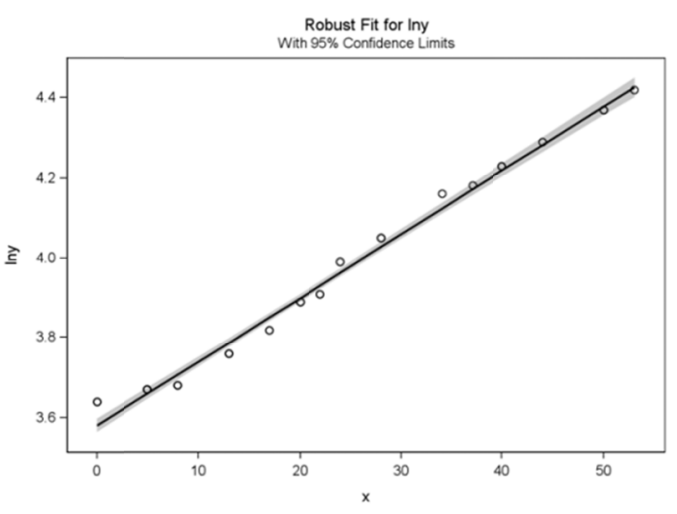

Fig. 5. Fit plot for lny
TABLE $X . \quad$ PARAMETER ESTIMATES FOR FAIR REGRESSION

\begin{tabular}{|c|c|c|c|c|c|c|c|}
\hline \multicolumn{7}{|c|}{ Parameter Estimates } \\
\hline Parameter & DF & Estimate & $\begin{array}{c}\text { Std. } \\
\text { Error }\end{array}$ & \multicolumn{2}{|c|}{$\begin{array}{c}\text { 95\% } \\
\text { Confidence } \\
\text { Limits }\end{array}$} & $\begin{array}{c}\text { Chi- } \\
\text { Square }\end{array}$ & $\begin{array}{c}\text { Pr }> \\
\text { ChiSq. }\end{array}$ \\
\hline Intercept & 1 & 3.5803 & 0.0086 & 3.563 & 3.597 & 171908 & $<0.0001$ \\
\hline $\mathrm{X}$ & 1 & 0.0160 & 0.0003 & 0.015 & 0.016 & 2162.9 & $<0.0001$ \\
\hline Scale & 1 & 0.0336 & & & & & \\
\hline
\end{tabular}

TABLE XI. PARAMETER ESTIMATES FOR FAIR REGRESSION

\begin{tabular}{|c|c|}
\hline \multicolumn{2}{|c|}{ Goodness-of-Fit } \\
\hline Statistic & Value \\
\hline R-Square & 0.9616 \\
\hline AICR & 12.3093 \\
\hline BICR & 17.8695 \\
\hline Deviance & 0.0121 \\
\hline
\end{tabular}

\section{F. Method Comparison}

Table XII shows the comparison of the five different methods. We summarized the output of the gained model with their parameter estimates.

TABLE XII. PARAMETER ESTIMATES COMPARISON

\begin{tabular}{|c|c|c|c|}
\hline $\begin{array}{c}\text { Parameter } \\
\text { Estimates }\end{array}$ & Model & R-Square & AIC \\
\hline Exponential Fit & $\begin{array}{c}y=35.9735 e^{0.0160 x} \\
\text { or in a linear form } \\
\ln (y)=3.5827+0.0160 x\end{array}$ & 0.988339 & 1.064 .925 \\
\hline $\begin{array}{c}\text { Robust } \\
\text { Regression }\end{array}$ & $\ln y=3.5729+0.0162 x$ & 0.7894 & 282.413 \\
\hline Robust Huber & $\ln y=3.5799+0.0160 x$ & 0.9577 & 243.544 \\
\hline Robust Cauchy & $\ln y=3.5798+0.0160 x$ & 0.4797 & 3.779 .854 \\
\hline Robust Fair & $\ln y=3.5803+0.0160 x$ & 0.9616 & 123.093 \\
\hline
\end{tabular}

\section{DISCUSSION AND CONCLUSION}

The main objective of this research is to compare the parameter estimate between several proposed calculations and also to find the best calculation which can represent the data through modeling techniques. We have given an example of cell doubling data by using PROC NLIN and PROC ROBUSTREG. In this paper, five different methods were used (Table XII): (i) Exponential fit (ii) Robust regression (iii) Robust (weighted) Huber (iv) Robust (weighted) Cauchy (v) Robust (weighted) fair. This paper provides only a preliminary overview of the above mentioned different techniques that can be employed. From the results, we can see that the exponent fit shows a very good fitting result, followed by robust regression weighted by fair techniques. Both methods produced the highest $\mathrm{R}^{2}$ and the lowest AIC. This indicates that exponential fit is the best method, followed by robust fair regression. The other methods fit the model poorly. This may be due to some outliers through the output. The best way to handle outliers is to delete them from the set of data and then rerun to the analysis once again. To keep the efficiency and accuracy of the proposed model, it is necessary to have a good way of calculation with some improvements of the proposed strategy. The exponential fit reveals the findings more explicitly compared to the other proposed methods. 


\section{ACKNOWLEDGMENT}

Authors would like to express their gratitude to Universiti Sains Malaysia for providing the research funding (Grant no.1001/PPSG/8012278, School of Dental Sciences, Universiti Sains Malaysia)

\section{REFERENCES}

[1] N. R. Draper, H. Smith, Applied Regression Analysis, Wiley Eastern, 1998

[2] R. J. Tallarida, R. B. Murray. Exponential growth,and decay, Manual of Pharmacologic Calculations, Springer, 1987

[3] R. Tahmasbi, S. Rezaei, "A two-parameter lifetime distribution with decreasing failure rate", Computational Statistics \& Data Analysis,Vol. 52, No. 8, pp. 3889-390, 2008

[4] A. Schneider, G. Hommel, M. Blettner, "Linear Regression Analysis", Deutsches Arzteblatt International, Vol. 107, No. 44, pp. 776-82, 2010

[5] D. C. Montgomery, E. Peck, G. Vining, Introduction to linear regression analysis, 3rd Edition, John Wiley and Sons, 2003

[6] R. Gupta, D. Kundu, "Generalized Exponential Distributions", Australian and New Zealand Journal of Statistics, Vol. 41, No. 2, pp. 173-188, 1999

[7] K. Adamidis, S. Loukas, "A lifetime distribution with decreasing failure rate", Statistics \& Probability Letters, Vol. 39, No. 1, pp. 35-42,1998

[8] D. Kus, "A new lifetime distribution distributions", Computational Statistics and Data Analysis, Vol. 11, No. 9, pp. 4497-4509, 2007

[9] F. Louzada-Neto, "Poly hazard regression models for lifetime data", Biometric,Vol. 55, No. 4, pp. 1281-1285, 1999

[10] J. U. Kreft, G. Booth, J. W. T. Wimpenny, "BacSim, a simulator for individual-based modeling of bacterial colony growth", Microbiology, Vol. 144, No. 12, pp. 3275-3287, 1998 